\title{
Rates of Seed Treatment Insecticides and Control of Stewart's Wilt in Sweet Corn
}

\author{
J. K. Pataky, P. M. Michener, and N. D. Freeman, University of Illinois, Department of Crop Sciences, Urbana \\ 61801; J. M. Whalen, Department of Entomology and Applied Ecology, University of Delaware, Newark 19716; \\ J. A. Hawk and T. Weldekidan, Department of Plant and Soil Science, University of Delaware, Newark 19716; and \\ R. H. Teyker, Del Monte Foods, Agricultural Research, Rochelle, IL 61018-9990
}

\begin{abstract}
Pataky, J. K., Michener, P. M., Freeman, N. D., Whalen, J. M., Hawk, J. A., Weldekidan, T., and Teyker, R. H. 2005. Rates of seed treatment insecticides and control of Stewart's wilt in sweet corn. Plant Dis. 89:262-268.

Neonicotinoid insecticides applied as seed treatments reduce the incidence of Stewart's wilt. The objectives of this study were to examine the efficacy of different rates of seed treatment insecticides to control Stewart's wilt on susceptible sweet corn hybrids and to compare the economic value of Stewart's wilt control in sweet corn grown for processing and fresh market. Clothianidin (Poncho), imidacloprid (Gaucho), and thiamethoxam (Cruiser) applied to seed at rates ranging from 0.125 to $1.25 \mathrm{mg}$ a.i. per kernel were evaluated in 11 field trials in Illinois and Delaware from 2000 to 2003. Incidence of Stewart's wilt was significantly lower when seed was treated with insecticides than when plants were grown from nontreated seed in all but one trial. The level of control usually was between 50 and $90 \%$. Small but statistically significant differences in incidence of systemically infected plants occurred among rates of insecticides in all trials except those in 2001. Usually, incidence of systemic Stewart's wilt was lower when higher rates of insecticides were applied; however, increasing the rate of insecticides from $0.125 \mathrm{mg}$ a.i. to $1.25 \mathrm{mg}$ a.i. per kernel had a relatively small effect on the level of Stewart's wilt control compared with the difference between treated and nontreated sweet corn seed. Based on a regression analysis, the lowest rates of the insecticides provided 64 to $72 \%$ control. The level of control increased about $1.85 \%$ with each additional $0.1 \mathrm{mg}$ a.i. of insecticide per kernel from $0.125 \mathrm{mg}$ a.i. to $1.25 \mathrm{mg}$ a.i. Clothianidin provided an 8 or $9 \%$ higher level of control than thiamethoxam or imidacloprid at the same rate. Recommendations for application of seed treatment insecticides to processing and fresh market sweet corn differed somewhat due to substantial differences in the value of the crops. Based on estimated costs of $\$ 6$ to $\$ 12$ per 0.4 ha for the seed treatments, the economic break even point (i.e., cost of control $=$ value from control) occurred in the range of 3 to $6 \%$ Stewart's wilt incidence for processing sweet corn valued at $\$ 325$ per 0.4 ha and at about $1 \%$ Stewart's wilt incidence for fresh market sweet corn valued at $\$ 1,625$ per 0.4 ha. Relatively small differences in levels of control conferred by commercially available rates of clothianidin ( $0.25 \mathrm{mg}$ a.i. per kernel) and thiamethoxam $(0.125 \mathrm{mg}$ a.i. per kernel) were of little consequence in processing sweet corn but had considerable economic value in fresh market sweet corn.
\end{abstract}

Corn flea beetles, Chaetocnema pulicaria, are vectors of Erwinia stewartii (Syn. Pantoea stewartii), which causes Stewart's wilt of corn. Yield reductions from Stewart's wilt can be minimized by delaying infection until later growth stages. Yield of sweet corn is not affected or yield losses are minimal if resistant hybrids are infected after the three- to fiveleaf stages or if moderately resistant hybrids are infected after the five- to sevenleaf stages (16). Yield of susceptible or moderately susceptible sweet corn hybrids can be affected if plants are infected before the early tassel stage (16). Yield is reduced

Corresponding author: J. K. Pataky

E-mail: j-pataky@uiuc.edu

Accepted for publication 11 October 2004.

DOI: 10.1094/PD-89-0262

(C) 2005 The American Phytopathological Society about $0.9 \%$ for each $1 \%$ incidence of systemically infected plants (7).

Host resistance restricts the movement of E. stewartii in plants (5); however, resistance may not inhibit short-distance movement of $E$. stewartii in very young plants (10). When flea beetles feed on plants prior to the two- or three-leaf stage, the growing point of corn plants may be only a few centimeters from feeding wounds. If the growing point becomes infected, main stalks are killed, tillers grow profusely, and ears are not produced (12). Main stalk death occurs even in the most resistant sweet corn hybrids, although the incidence of main stalk death decreases with increasing levels of resistance (12).

Neonicotinoid insecticides applied as seed treatments reduce the incidence of Stewart's wilt by killing flea beetles before plants are infected by E. stewartii $(1,9,11,14)$. Applications of imidacloprid and thiamethoxam at $0.675 \mathrm{mg}$ a.i. or 0.8 $\mathrm{mg}$ a.i. per kernel reduced the incidence of
Stewart's wilt by about one-half to fivesixths in 17 field trials in Illinois in 1998 and 1999 (14). Applications of imidacloprid at $0.4 \mathrm{mg}$ a.i. and $0.675 \mathrm{mg}$ a.i. per kernel and thiamethoxam at $0.54 \mathrm{mg}$ a.i. per kernel reduced the incidence of Stewart's wilt at the six-leaf stage by one-half to five-sixths in two field trials in New York in 2000; however, when the same plots were evaluated at the 10-leaf stage, control ranged from about 5 to $88 \%$ (9). The level of control and the length of time that plants are protected from Stewart's wilt may be improved when higher rates of insecticides are applied to seed. However, in laboratory tests, Kuhar et al. (9) observed some cases of reduced germination when $0.675 \mathrm{mg}$ a.i. imidacloprid per kernel was applied to sweet corn seed. Thus, it would be useful to determine if levels of Stewart's wilt control are affected by rates of seed treatment insecticides.

The objectives of this study were to examine the efficacy of different rates of seed treatment insecticides in controlling Stewart's wilt on susceptible sweet corn hybrids and to compare the economic value of Stewart's wilt control via seed treatment insecticides in sweet corn grown for processing and fresh market.

\section{MATERIALS AND METHODS}

Rates of three seed treatment insecticides (clothianidin, imidacloprid, and thiamethoxam) from 0.125 to $1.25 \mathrm{mg}$ a.i. per kernel were evaluated in 11 field trials in Illinois and Delaware from 2000 to 2003. Rates of insecticides, number of treatments, number of replicates, and size of experimental units varied slightly among trials. A total of 17 trials were planted in Urbana, IL, from 2000 to 2003, in Manito, IL, in 2000, in Newark, DE, in 2001, and in Brownstown, IL, in 2002. Data were not analyzed from six trials in which incidence of systemic Stewart's wilt was between 1 and 5\% in the nontreated check treatment because the level of disease was too low to effectively differentiate insecticide treatments.

One or two of three Stewart's wilt susceptible sweet corn hybrids, 'Jubilee', 'Lumina', or 'Supersweet Jubilee', were planted at each location in each year. When more than one hybrid was planted at the same time and location, the hybrids were arranged as separate trials. Trials were planted in late April, mid-June to 
early July, or late July so that plants would be infected naturally by $E$. stewartii transmitted by the overwintering generation, the first summer generation, or the second/third summer generations of corn flea beetles, respectively (Figs. 1 to 4 ).

Each trial consisted of 10 or 11 treatments, which included a nontreated check and two to four rates of each of the three insecticides (Figs. 1 to 4). Seed were treated with clothianidin (Poncho, Gustafson LLC, Plano, TX) at rates from 0.125 to $0.5 \mathrm{mg}$ a.i. per kernel, imidacloprid (Gaucho $480 \mathrm{FS}$ or Gaucho 600FS, Gustafson
LLC) at rates from 0.16 to $1.25 \mathrm{mg}$ a.i. per kernel, and thiamethoxam (Cruiser FS, Syngenta Crop Protection, Greensboro, $\mathrm{NC}$ ) at rates from 0.125 to $1.08 \mathrm{mg}$ a.i. per kernel. Insecticides were applied to seed by personnel at Gustafson and Syngenta Crop Protection.

The experimental design was a randomized complete block in all trials with three or four replicates per trial. Experimental units consisted of four to eight rows spaced 76 or $91 \mathrm{~cm}$ apart. Rows were about $8.3 \mathrm{~m}$ long with about 30 to 45 plants per row. All plants were assessed visually for symptoms of systemic Stewart's wilt infection. Incidence of Stewart's wilt was calculated from 1,140 to 1,400 plants per treatment per trial except for the trials in 2002, in which there were 250 to 560 plants per treatment (Table 1).

Plants were infected naturally by $E$. stewartii transmitted by flea beetle vectors. The number of plants with symptoms of systemic Stewart's wilt was counted between the three- and seven-leaf stages except for the trials in Delaware in 2001, where infected plants were counted at harvest. Incidence (\%) of Stewart's wilt
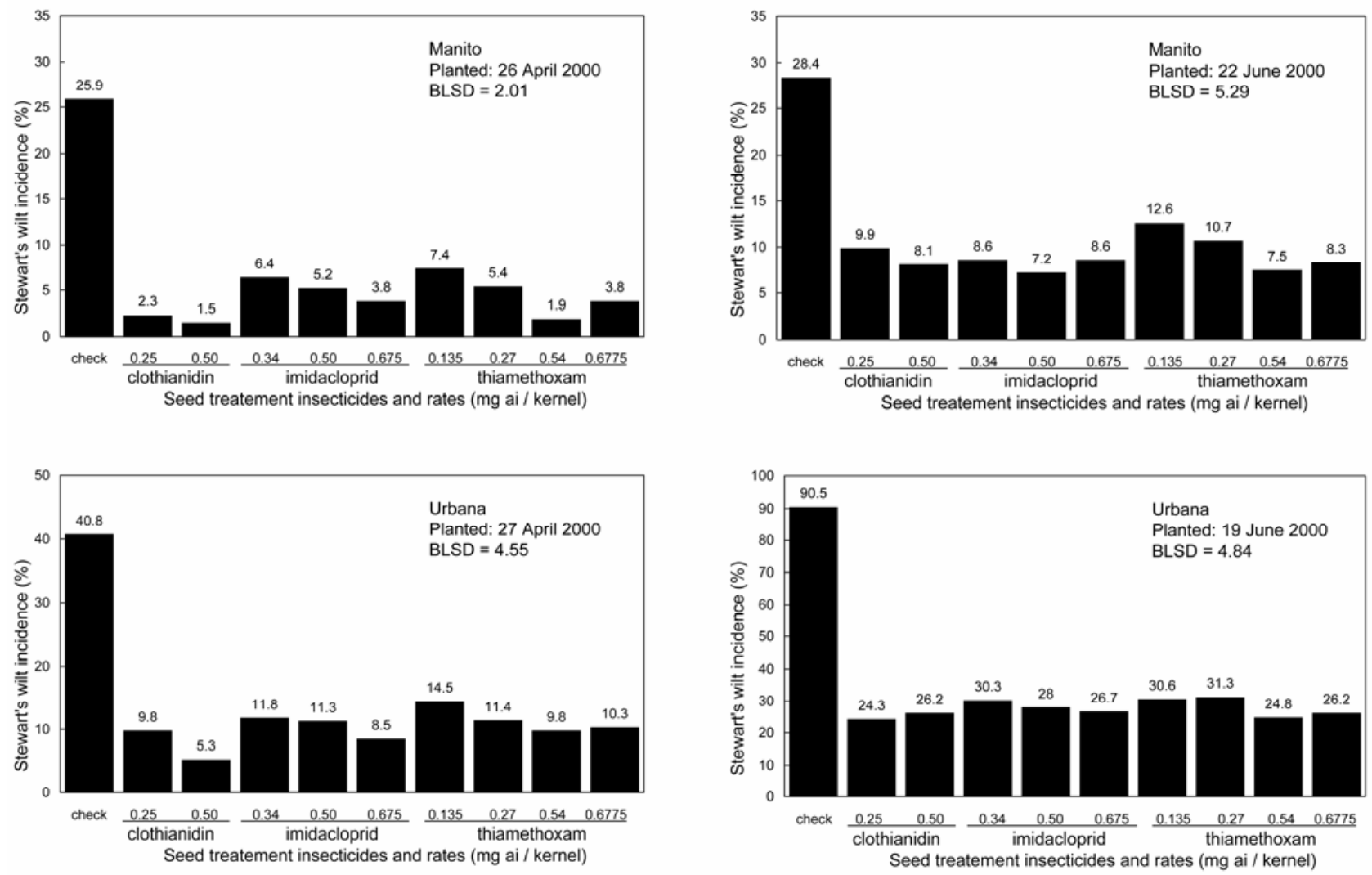

Fig. 1. Incidence of Stewart's wilt (\%) on seedlings of 'Jubilee' sweet corn grown from seed treated with various rates of three different insecticides. Erwinia stewartii was transmitted by the overwintering and the first summer generations of corn flea beetles in trials planted in April and June 2000 , respectively, in Manito and Urbana, IL.
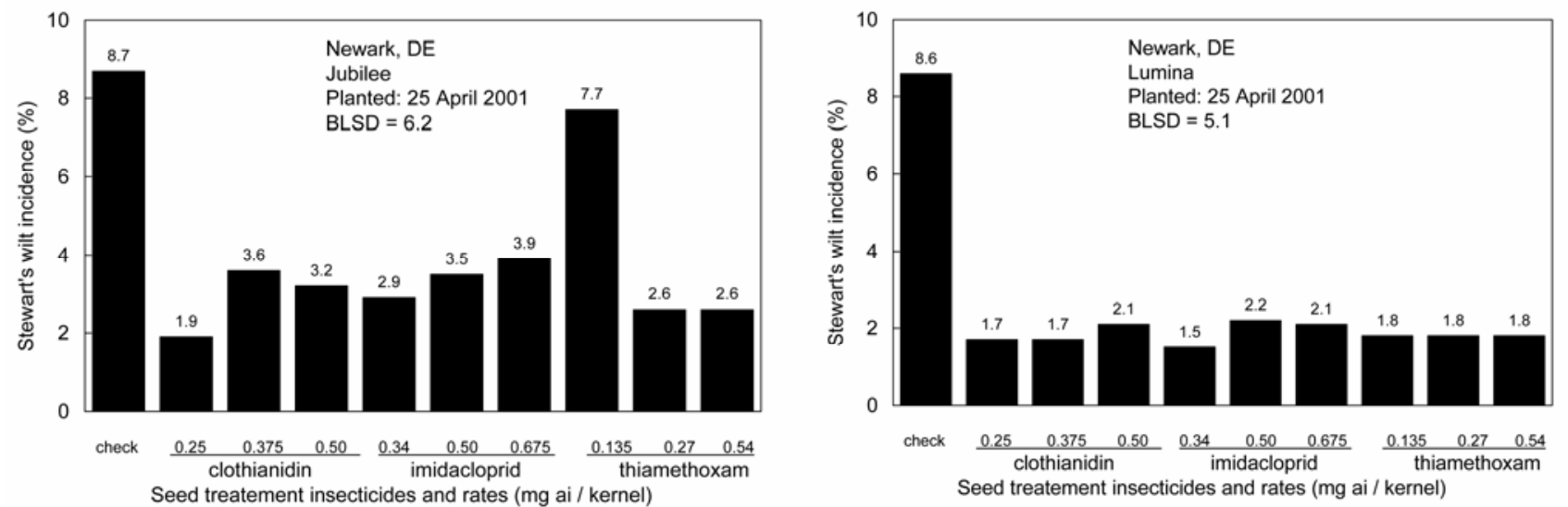

Fig. 2. Incidence of Stewart's wilt (\%) on mature plants of 'Jubilee' and 'Lumina' sweet corn grown from seed treated with various rates of three different insecticides. Erwinia stewartii was transmitted by the overwintering generation of corn flea beetles in trials planted in April 2001 in Newark, DE. 
was calculated for each experimental unit as: Incidence $(\%)=$ (number of plants systemically infected/total number of plants) $\times 100$.

Incidence for each treatment was calculated as a weighted mean based on the number of plants per experimental unit. The level of control (\%) was calculated from treatment means as a percentage of the nontreated check: Level of control (\%) $=100-[$ incidence treated/incidence nontreated check) $\times 100$ ].

Incidence of Stewart's wilt was analyzed by ANOVA for each trial. Treatments were compared by BLSD values $(k=100)$. Mean level of control $(\%)$ for each treatment from each trial was regressed on rates of insecticides, with insecticides as qualitative variables and rates as quantitative independent variables. Analyses were done with PROC GLM of SAS (SAS Institute, Cary, NC). Linear and curvilinear models were tested.

Incidence of Stewart's wilt on plants grown from treated seed was estimated for rates of clothianidin $(0.25 \mathrm{mg}$ a.i. per kernel) and thiamethoxam ( $0.125 \mathrm{mg}$ a.i. per kernel) that are available commercially for sweet corn. Incidence of Stewart's wilt also was estimated for imidacloprid at $0.675 \mathrm{mg}$ a.i. per kernel, a rate that was available commercially on sweet corn under certain circumstances (e.g., US EPA FIFRA Section 18 exemption). Incidence of Stewart's wilt on plants grown from treated seed was calculated as: Incidence treated $(\%)=$ incidence nontreated $(\%) \times$ $C$, where $C=$ level of control, as a proportion, predicted from the regression analysis of level of control and rates.
The economic value (\$ per $0.4 \mathrm{ha}$ ) of control of Stewart's wilt with commercially available rates of clothianidin and thiamethoxam was calculated separately for processing and fresh market sweet corn as: Economic value $=$ crop value $\times C \times$ (incidence nontreated $/ 100) \times 0.9$, where crop values were estimated at $\$ 325$ and

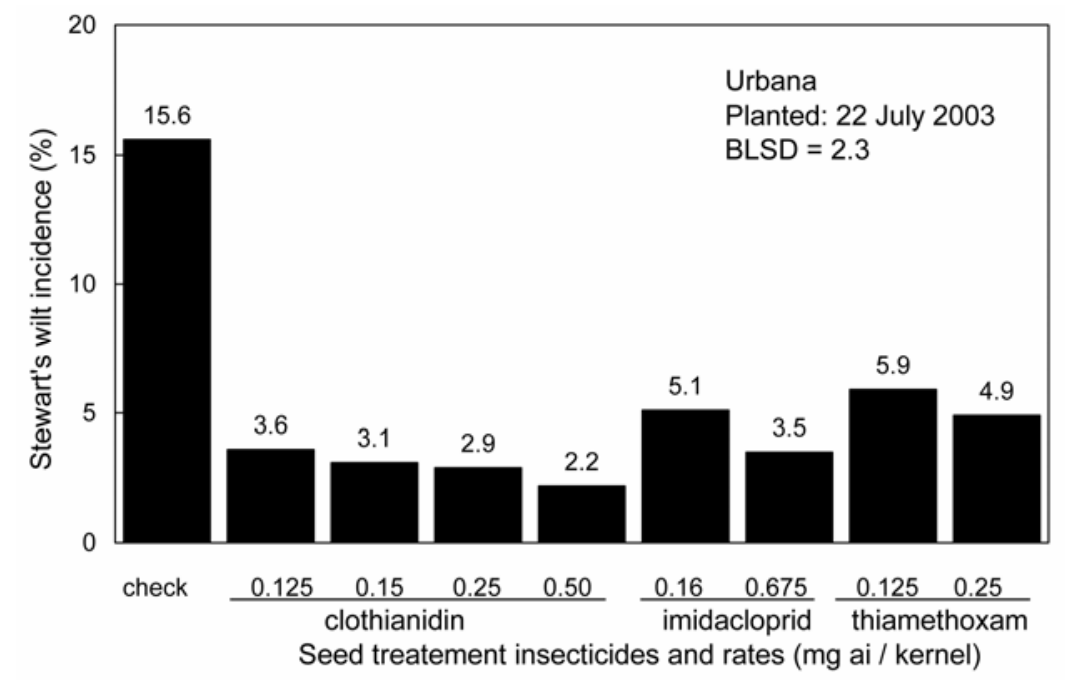

Fig. 4. Incidence of Stewart's wilt $(\%)$ on seedlings of 'Jubilee' sweet corn grown from seed treated with various rates of three different insecticides. Erwinia stewartii was transmitted by the second and third summer generations of corn flea beetles in trials planted 22 July 2003 in Urbana, IL.
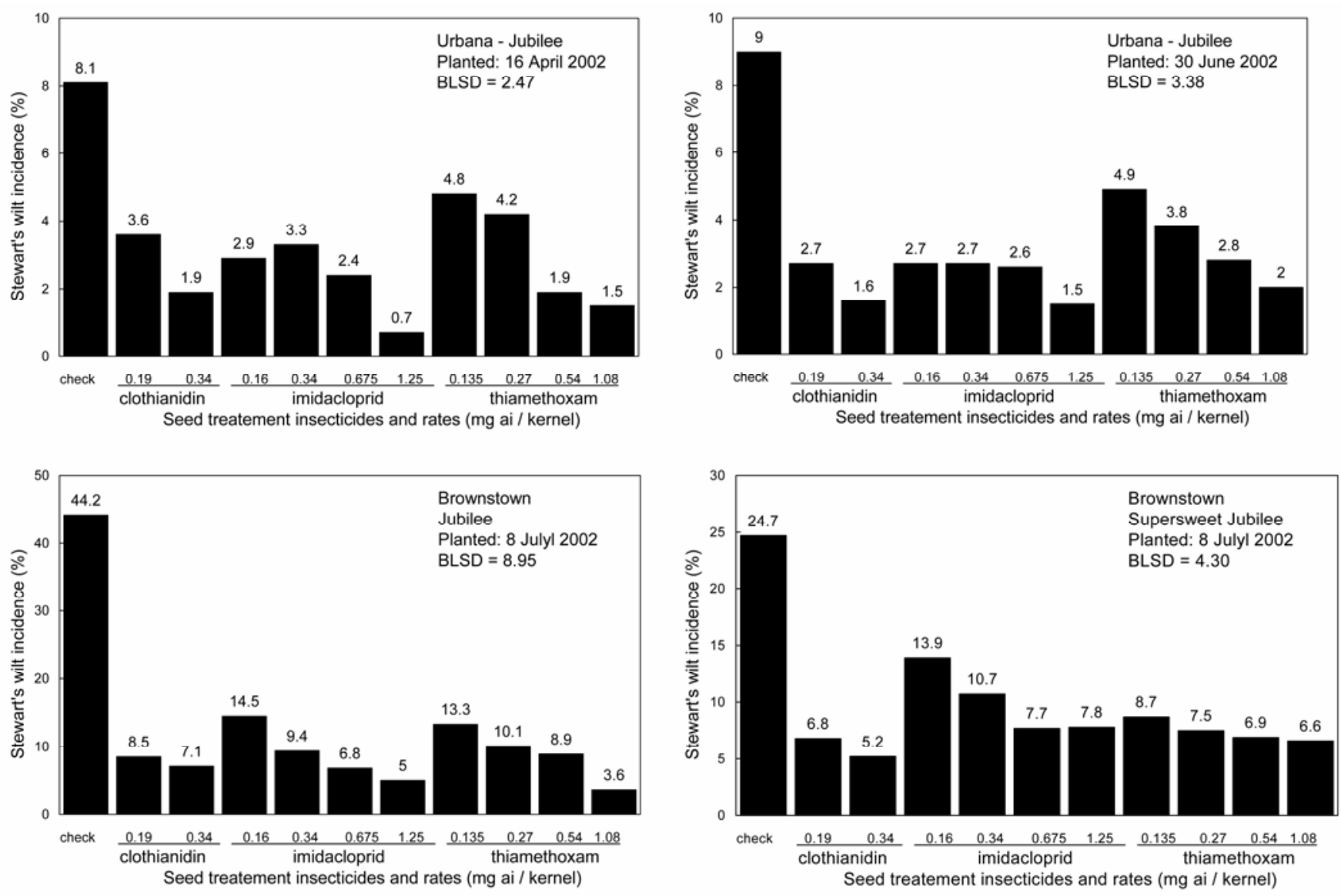

Fig. 3. Incidence of Stewart's wilt (\%) on seedlings of 'Jubilee' and 'Supersweet Jubilee' sweet corn grown from seed treated with various rates of three different insecticides. Erwinia stewartii was transmitted by the overwintering and the first summer generations of corn flea beetles in trials planted in April and June /July 2002, respectively, in Urbana and Brownstown, IL. 
$\$ 1,625$ per 0.4 ha for processing and fresh market sweet corn, respectively; $C=$ level of control as a proportion predicted from the regression analysis of level of control and rates; (incidence nontreated/100) = incidence in the absence of control as a proportion; and $0.9=$ a constant from the linear regression that described the relationship between Stewart's wilt incidence and percent reduction in yield (7). The value of processing sweet corn was estimated to be $\$ 325$ per 0.4 ha based on an average yield of $5.9 \mathrm{t}$ per 0.4 ha $(6.5$ ton per A) and an average price of $\$ 55.12$ per $t$ ( $\$ 50$ per ton). The value of fresh market sweet corn was estimated to be $\$ 1,625$ per 0.4 ha based on an average yield of 325 crates of 50 ears per 0.4 ha and an average price of $\$ 5$ per crate.

\section{RESULTS}

Incidence and level of control in field trials. Data were not analyzed from six trials in which incidence of Stewart's wilt was between 1 and 5\% in the nontreated check. This included four trials in Illinois in 2001 and two trials planted with the hybrid 'Supersweet Jubilee' in Illinois in 2002. In all trials in which Stewart's wilt was above $5 \%$, incidence of systemic infection was significantly lower when seed were treated with insecticides than when plants were grown from nontreated seed except for the early-planted trial in Delaware in 2001 (Figs. 1 to 4). Levels of control ranged from $41 \%$ for seed treated with $0.135 \mathrm{mg}$ a.i. thiamethoxam per kernel in the early-planted trial in Urbana in 2002 (Fig. 3) to $94 \%$ for seed treated with 0.5 $\mathrm{mg}$ a.i. clothianidin per kernel in the earlyplanted trial in Manito in 2000 (Fig. 1).

Small but statistically significant differences in incidence occurred among rates of insecticides in all trials except those in 2001. Incidence usually was lower when seed were treated with higher rates of insecticides than with lower rates. For example, in the early-planted trial at Manito in 2000, incidence of Stewart's wilt was significantly lower when seed were treated with 0.25 and $0.5 \mathrm{mg}$ a.i. clothianidin and $0.54 \mathrm{mg}$ a.i. thiamethoxam than when seed were treated with $0.34 \mathrm{mg}$ a.i. imidacloprid and 0.135 and $0.27 \mathrm{mg}$ a.i. thiamethoxam (Fig. 1). Similarly, in the early-planted trial in Urbana in 2002, incidence was significantly lower when seed were treated with $1.25 \mathrm{mg}$ a.i. imidacloprid and $1.08 \mathrm{mg}$ thiamethoxam than with 0.135 and 0.27 mg a.i. thiamethoxam (Fig. 3). Although these differences were statistically significant, they usually were relatively small. Actual incidence of Stewart's wilt never differed more than $10 \%$ among seed treated with insecticides in any given trial (Figs. 1 to 4). Over all trials, levels of control generally ranged from 50 to $90 \%$ (Fig. 5). Within most trials, the difference between the highest and lowest level of control was less than 25\%; however, the range in level of control was 35 to $50 \%$ when incidence of Stewart's wilt in nontreated checks was low (e.g., below 10\%) or the number of plants from which incidence was estimated (i.e., sample size) was low (Table 1).

Regression analysis of levels of control. Effects of insecticides and rates applied to seed were statistically significant, but the interaction of rates and insecticides was not significant when level of control (\%) was analyzed by regression. Despite the significant effects of insecticides and rates, only $34 \%$ of the variation in level of control was explained by the independent variables. Curvilinear models did not explain a greater amount of variation than linear models when rates of seed treatment insecticides ranged from $0.125 \mathrm{mg}$ a.i. to $1.25 \mathrm{mg}$ a.i. per kernel.

Based on the regression analysis, clothianidin provided about $8 \%$ more control than the other insecticides at the same rate of application (Fig. 5). The $0.25 \mathrm{mg}$

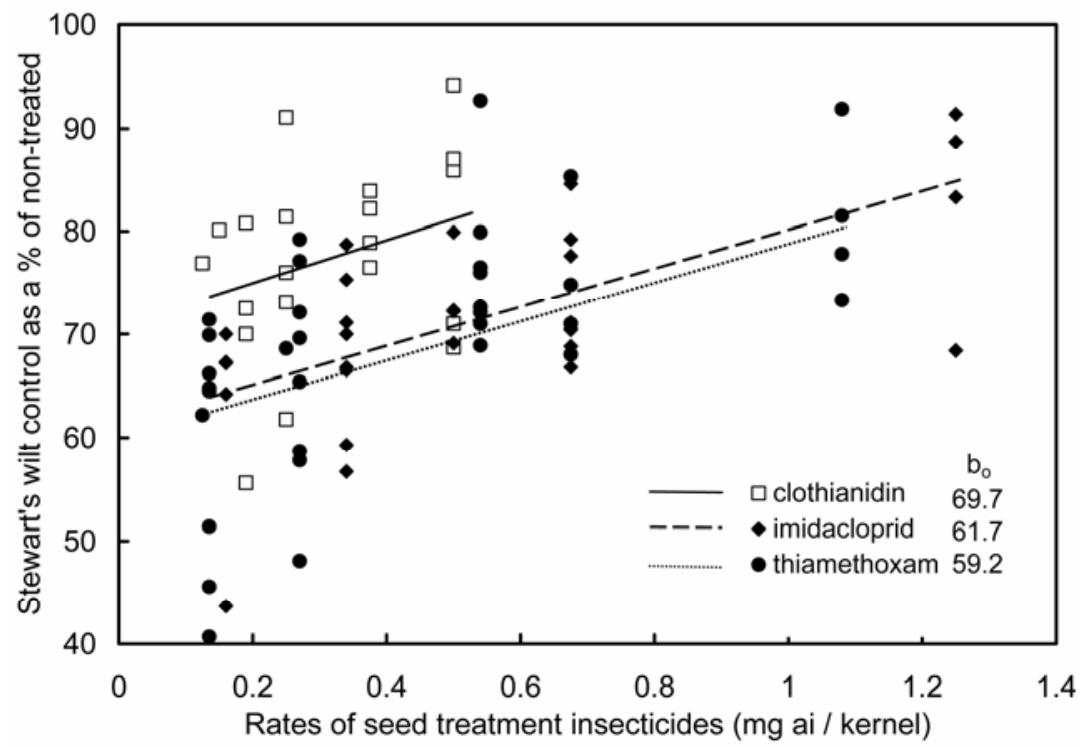

Fig. 5. Control of Stewart's wilt (as a percentage of nontreated) on sweet corn grown from seed treated with various rates of three different insecticides in 11 trials in Illinois and Delaware from 2000 to 2003. The slope coefficient of the regression of level of control (\%) on rates (mg a.i. per kernel) of insecticides did not differ among the three insecticides $\left(b_{1}=18.5\right)$. The coefficient of determination was 0.34 .

Table 1. Range of control of Stewart's wilt, incidence of systemic infection in nontreated check plots, and sample size in 11 trials in Illinois and Delaware from 2000 to 2003 in which clothianidin, imidacloprid, and thiamethoxam were applied to seed of susceptible sweet corn hybrids at rates from 0.125 to 1.25 mg a.i. per kernel

\begin{tabular}{|c|c|c|c|c|c|c|}
\hline Year & Planting date & Location & Hybrid & $\begin{array}{c}\text { Approximate } \\
\text { sample size per } \\
\text { treatment }\end{array}$ & $\begin{array}{c}\text { Stewart's wilt } \\
\text { incidence }(\%) \text { in } \\
\text { nontreated check }\end{array}$ & $\begin{array}{c}\text { Range of control } \\
(\%)^{\mathrm{a}}\end{array}$ \\
\hline \multirow[t]{4}{*}{2000} & April 26 & Manito, IL & Jubilee & 1,220 & 28 & $72-94$ \\
\hline & April 27 & Urbana, IL & Jubilee & 1,290 & 41 & $65-87$ \\
\hline & June 19 & Urbana, IL & Jubilee & 1,370 & 91 & $65-73$ \\
\hline & June 22 & Manito, IL & Jubilee & 1,140 & 26 & $52-72$ \\
\hline \multirow[t]{2}{*}{2001} & April 25 & Newark, DE & Lumina & 1,200 & 9 & $75-81$ \\
\hline & April 25 & Newark, DE & Jubilee & 1,200 & 9 & $55^{\mathrm{b}}-82$ \\
\hline \multirow[t]{4}{*}{2002} & April 16 & Urbana, IL & Jubilee & 520 & 8 & $41-91$ \\
\hline & June 30 & Urbana, IL & Jubilee & 560 & 9 & $46-83$ \\
\hline & July 8 & Brownstown, IL & Jubilee & 350 & 44 & $67-92$ \\
\hline & July 8 & Brownstown, IL & Supersweet Jubilee & 250 & 25 & $44-79$ \\
\hline 2003 & July 22 & Urbana, IL & Jubilee & 1,400 & 16 & $67-86$ \\
\hline
\end{tabular}

${ }^{a}$ Control $(\%)=100-[$ (incidence treated/incidence nontreated) $\times 100]$.

${ }^{\mathrm{b}}$ Excluding $0.135 \mathrm{mg}$ a.i. thiamethoxam per kernel for which control was only $11 \%$. 
rate of clothianidin provided about the same predicted level of control (i.e., about $75 \%$ control) as the $0.675 \mathrm{mg}$ rate of imidacloprid and thiamethoxam (Fig. 5). At the lowest rate tested for any of the insecticides $(0.125 \mathrm{mg}$ a.i. per kernel), the predicted levels of control were 72.4, 63.6, and $64.7 \%$ from clothianidin, imidacloprid, and thiamethoxam, respectively.
Based on a significant slope coefficient from the regression analysis $\left(b_{1}=18.5\right)$, the predicted level of control increased $1.85 \%$ for each additional $0.1 \mathrm{mg}$ a.i. of insecticide applied per kernel between $0.125 \mathrm{mg}$ a.i. and $1.25 \mathrm{mg}$ a.i. (Fig. 5). Based on this relationship, when Stewart's wilt was prevalent and the incidence of systemic infection in nontreated plots was

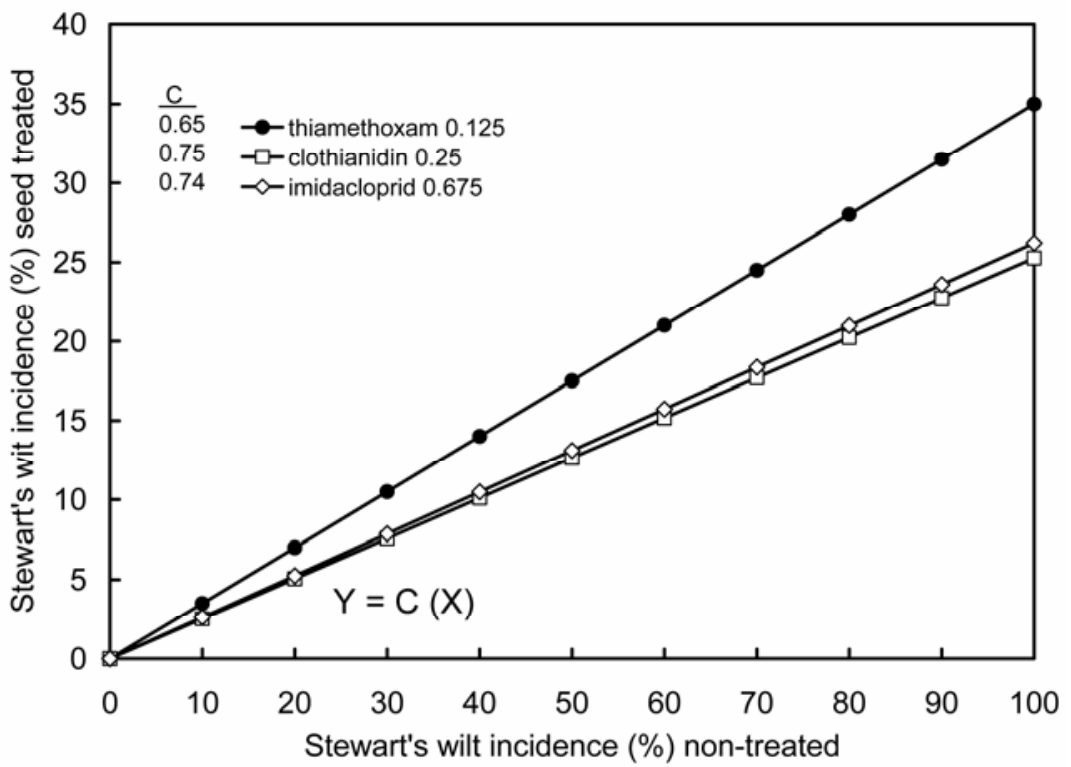

Fig. 6. Predicted incidence of Stewart's wilt (\%) when the seed treatment insecticides are applied at rates available commercially for sweet corn: thiamethoxam at $0.125 \mathrm{mg}$ a.i. per kernel, chlothianidin at $0.25 \mathrm{mg}$ a.i. per kernel, and imidacloprid at $0.675 \mathrm{mg}$ a.i. per kernel. Predicted incidence $(Y)$ calcuated as the incidence of Stewart's wilt $(X)$ in the absence of seed treatment multiplied by the level of control as a proportion $(C)$ for each seed treatment. Values of $C$ derived from the regression of level of control (\%) on rates of insecticides (see Figure 5 and text).

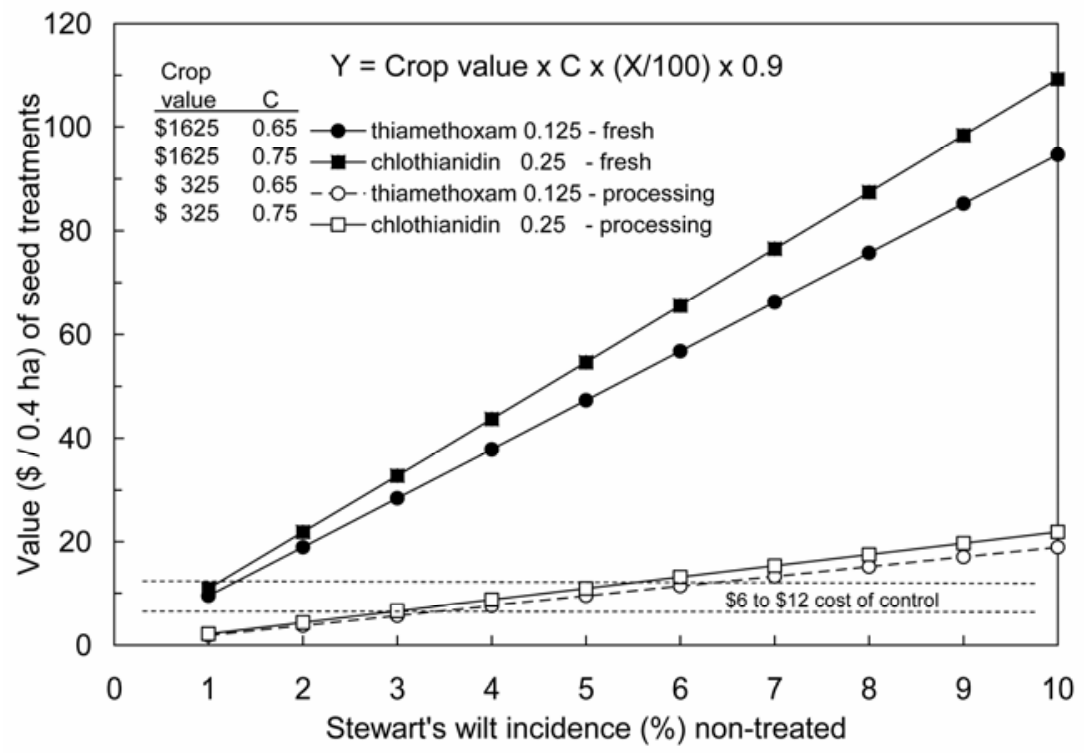

Fig. 7. Value (\$ per 0.4 ha) of controlling Stewart's wilt on processing or fresh market sweet corn by applying seed treatment insecticides at rates available commercially: thiamethoxam at $0.125 \mathrm{mg}$ a.i. per kernel or chlothianidin at $0.25 \mathrm{mg}$ a.i. per kernel. Value of control $(Y)$ based on an average crop value of $\$ 325$ per 0.4 ha for processing sweet corn and $\$ 1,625$ per 0.4 ha for fresh market sweet corn, $C=$ level of control from the seed treatment as a proportion, $(X / 100)=$ proportion of plants infected with Stewart's wilt in the absence of treatment, and $0.9=$ a constant from the regression that describes the relationship between Stewart's wilt incidence $(\%)$ and percent reduction in yield. Estimated costs of seed treatments were $\$ 6$ to $\$ 12$ per 0.4 ha.
90\% (e.g., Urbana, 19 June 2000), each additional $0.1 \mathrm{mg}$ a.i. of an insecticide beyond $0.125 \mathrm{mg}$ a.i. per kernel decreased incidence by about $1.7 \%$ (i.e., $90 \% \times$ 0.0185). When Stewart's wilt was less prevalent and incidence in nontreated plots was only $15 \%$ (e.g., Urbana, 22 July 2003), each $0.1 \mathrm{mg}$ a.i. of an insecticide beyond $0.125 \mathrm{mg}$ a.i. per kernel decreased incidence by only $0.3 \%$ (i.e., $15 \% \times$ 0.0185).

Differences in levels of control among commercially available rates of insecticides were of greater consequence as incidence of Stewart's wilt increased. When the incidence of Stewart's wilt in the absence of control was $10 \%$, the predicted incidence of Stewart's wilt on plants grown from seed treated with $0.25 \mathrm{mg}$ a.i. clothianidin, $0.675 \mathrm{mg}$ a.i. imidacloprid, or $0.125 \mathrm{mg}$ a.i. thiamethoxam ranged from 2.5 to $3.5 \%$ (Fig. 6). When the incidence of Stewart's wilt in the absence of control was $30 \%$ or more, the predicted incidence of Stewart's wilt was $7.5 \%$ on plants grown from seed treated with $0.25 \mathrm{mg}$ a.i. clothianidin or $0.675 \mathrm{mg}$ a.i. imidacloprid and $10.5 \%$ on plants grown from seed treated with $0.125 \mathrm{mg}$ a.i. thiamethoxam. A $3 \%$ difference in incidence could be economically important, especially in sweet corn grown for fresh market.

Economic value of control. The level of Stewart's wilt at which seed treatment insecticides were economical differed between processing sweet corn and fresh market sweet corn due to a large difference in the value of the crops (Fig. 7). When the incidence of Stewart's wilt on processing sweet corn was between 3 and $6 \%$ in the absence of control, the predicted value of controlling Stewart's wilt with $0.25 \mathrm{mg}$ a.i. clothianidin or $0.125 \mathrm{mg}$ a.i. thiamethoxam ranged from $\$ 5.7$ to $\$ 13.1$ per 0.4 ha. In comparison, the predicted value of controlling Stewart's wilt on fresh market sweet corn with $0.25 \mathrm{mg}$ a.i. clothianidin or $0.125 \mathrm{mg}$ a.i. thiamethoxam was $\$ 9.5$ and $\$ 10.9$ per 0.4 ha, respectively, when the incidence of Stewart's wilt was only $1 \%$ in the absence of control. Thus, based on estimated costs of $\$ 6$ to $\$ 12$ per 0.4 ha for these seed treatments, the economic break even point (i.e., cost of control = value from control) occurred in the range of 3 to $6 \%$ Stewart's wilt incidence for processing sweet corn and at about $1 \%$ Stewart's wilt incidence for fresh market sweet corn (Fig. 7).

The difference in the value of different levels of control predicted from the commercially available rates of clothianidin and thiamethoxam also was accentuated by the large difference in the value of fresh market and processing sweet corn. Based on the regression analysis of levels of control and rates of insecticides (Fig. 5), control was about $10 \%$ greater when $0.25 \mathrm{mg}$ a.i. clothianidin was applied to seed than when $0.125 \mathrm{mg}$ a.i. thiamethoxam was applied, i.e., $75 \%$ control versus $65 \%$ con- 
trol predicted from the regression. The value of this $10 \%$ difference was minimal in processing sweet corn but substantial in fresh market sweet corn (Fig. 8). For example, when Stewart's wilt incidence in the absence of control was $10 \%$, the $10 \%$ difference in the level of control from 0.25 $\mathrm{mg}$ a.i. clothianidin and $0.125 \mathrm{mg}$ a.i. thiamethoxam had a value of $\$ 2.9$ per 0.4 ha for processing sweet corn and $\$ 14.6$ per 0.4 ha for fresh market corn (Fig. 8). When incidence in the absence of control was $30 \%$, the $10 \%$ difference in the level of control from $0.25 \mathrm{mg}$ a.i. clothianidin and $0.125 \mathrm{mg}$ a.i. thiamethoxam had a value of $\$ 8.8$ per 0.4 ha for processing sweet corn and $\$ 43.9$ per 0.4 ha for fresh market sweet corn (Fig. 8).

\section{DISCUSSION}

Incidence of systemic Stewart's wilt was reduced by half or more when seed of susceptible sweet corn hybrids were treated with neonicotinoid insecticides: clothianidin, imidacloprid, or thiamethoxam. These results corroborate previous evaluations of control of Stewart's wilt with these insecticides $(9,11,14)$. Different rates of insecticides from $0.125 \mathrm{mg}$ a.i. to $1.25 \mathrm{mg}$ a.i. per kernel had a relatively small effect on the level of Stewart's wilt control compared with whether or not sweet corn seed were treated with one of the insecticides. Based on a regression analysis of levels of control and insecticide rates, the lowest rates of the insecticides provided 64 to $72 \%$ control. Levels of control increased about $1.85 \%$ with each $0.1 \mathrm{mg}$ a.i. of insecticide per kernel from $0.125 \mathrm{mg}$ a.i. to $1.25 \mathrm{mg}$ a.i. Clothianidin provided an 8 or $9 \%$ higher level of control than thiamethoxam or imidacloprid applied at the same rate.

Based on our results, recommendations for application of insecticide seed treatments differ slightly between sweet corn grown for processing and fresh market. In processing sweet corn with a crop value of about $\$ 325$ per acre, seed treatment insecticides were economical in situations where incidence of systemic Stewart's wilt was about 3 to $6 \%$ or higher in the absence of control. In fresh market sweet corn with a value of about $\$ 1,625$ per 0.4 ha, seed treatment insecticides were economical if Stewart's wilt incidence was $1 \%$ or greater in the absence of control.

Disease control decisions also are affected by the utility of the decision, i.e., the measure of satisfaction from the decision (6). The decision to treat seed with insecticides should have greater utility for fresh market sweet corn growers than for processing sweet corn growers because the higher crop value of fresh market sweet corn creates a greater risk (i.e., greater potential economic loss) associated with yield reductions due to Stewart's wilt. Thus, seed treatment insecticides are more likely to be beneficial to fresh market sweet corn than to processing sweet corn in situations where growers are uncertain about the occurrence of Stewart's wilt. In six of our 17 trials, incidence of Stewart's wilt was between 1 and 5\% in nontreated check plots. In those six trials, the economic value of controlling Stewart's wilt with seed treatment insecticides was minimal for processing sweet corn; however, the seed treatments probably were economically advantageous for fresh market sweet corn. Similarly, relatively small differences in levels of control between commercially available rates of clothianidin and thiamethoxam that were predicted from our regression model were of little consequence in processing sweet corn but could be substantial in fresh market sweet corn.

Variation in the level of control that we observed among these trials was similar to the variation observed in previous field evaluations of Stewart's wilt control with neonicotinoid insecticide seed treatments $(9,14)$. In our study, control varied among trials from 41 to $81 \%$ when seed were treated with the lowest rates of insecticides ( 0.125 to $0.38 \mathrm{mg}$ a.i.), from 55 to $92 \%$ when seed were treated with intermediate rates ( 0.5 to $0.675 \mathrm{mg}$ a.i.), and from 68 to $92 \%$ when seed were treated with the highest rates (1.08 to $1.25 \mathrm{mg}$ a.i.). Previously, Pataky et al. (14) observed 75 to $85 \%$ control from imidacloprid or thiamethoxam applied at rates of approximately 0.675 or $0.80 \mathrm{mg}$ a.i. per kernel when trials in Illinois were planted before 1 June 1998 and 1999 and infection presumably was the result of large overwintering generations of flea beetles. Control ranged from 50 to $70 \%$ in trials planted after July 1 when the bacterium was carried by the first summer generation of the insect. Kuhar et al. (9) observed 58 to $88 \%$ control from imidacloprid at $0.4 \mathrm{mg}$ a.i. and $0.675 \mathrm{mg}$ a.i. per kernel and thiamethoxam at $0.54 \mathrm{mg}$ a.i. per kernel in trials planted before 2 June 2000 in New York. Some of the variation in our trials resulted from small sample sizes and the difficulty of precisely estimating low percentages (e.g., incidence below 10\%) from binomial data (i.e., number of Stewart's wilt infected plants). Consequently, the coefficient of determination from the regression of level of control on rates of insecticide was relatively low $\left(r^{2}=0.34\right)$. Nonetheless, we believe that the predicted values from the regression model provide a useful estimate from which to consider decisions about the use of these insecticide seed treatments in sweet corn.

Calculation of the economic benefit from controlling Stewart's wilt with seed treatment insecticides should include potentially harmful or beneficial secondary effects of these treatments. The neonicotinoid insecticides are efficacious against of a wide range of sucking and chewing pests of corn that include dipteran, coleopteran, homopteran, and lepidopteran insects (1). Therefore, the economic benefit of neonicotinoid insecticide seed treatments may extend beyond the control of Stewart's wilt when certain other insect pests are problematic in sweet corn. Potentially harmful effects of neonicotinoid insecticide seed treatments on sweet corn seed germination and emergence are not well established and are in need of further study. In a laboratory sand test, Kuhar et al. (9) observed about a $10 \%$ reduction in germination of

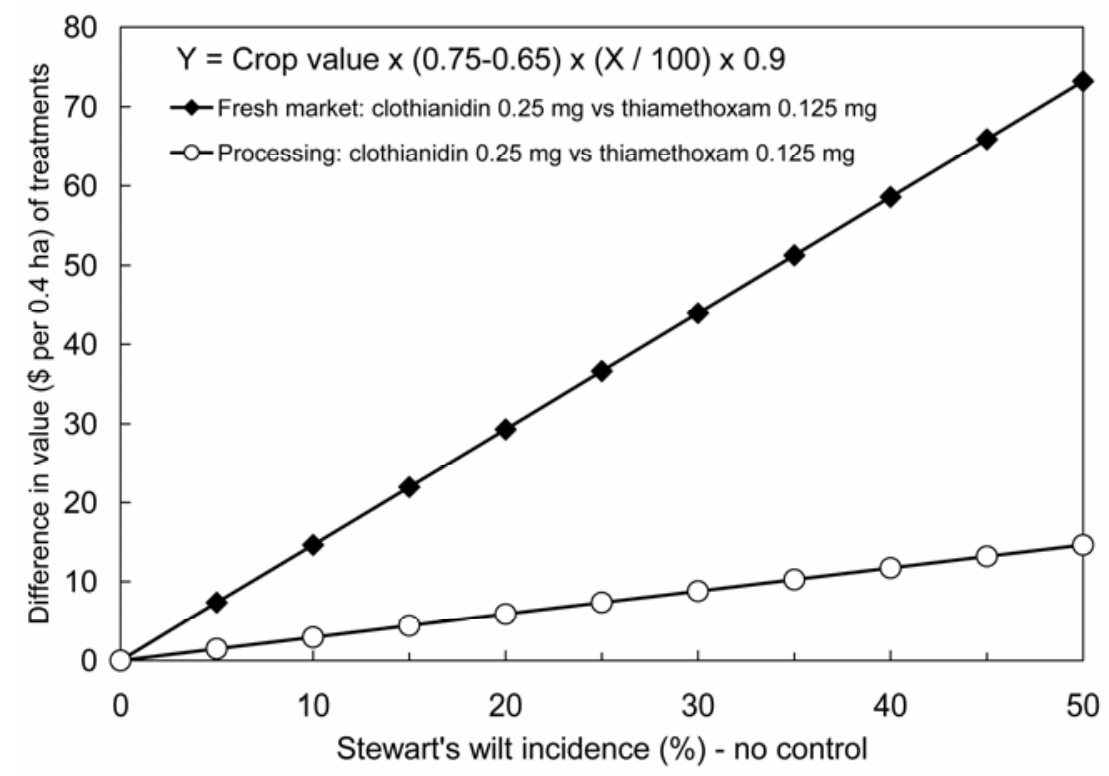

Fig. 8. Difference in the value ( $\$$ per 0.4 ha) of controlling Stewart's wilt by applying clothianidin at $0.25 \mathrm{mg}$ a.i. per kernel or thiamethoxam at $0.125 \mathrm{mg}$ a.i. per kernel to sweet corn seed when incidence of Stewart's wilt in the absence of control ranges from 0 to $50 \%$. Difference in value of control treatments ( $\$$ per 0.4 ha) based on average crop values of $\$ 1,625$ per 0.4 ha for fresh market sweet corn and $\$ 325$ per 0.4 ha for processing sweet corn. 
aged seed of 'Dynamo' and non-aged seed of 'Sprint' when treated with $0.675 \mathrm{mg}$ a.i. imidacloprid. They observed no effect of the insecticide on seed of 'Bonus', nonaged seed of 'Dynamo', or aged seed of 'Sprint'. Jonitz and Leist (8) reported no effect of $1.0 \mathrm{mg}$ a.i. of clothianidin or imidacloprid on emergence of field corn seed evaluated in the International Seed Trade Association (ISTA) standard cold test. In an ISTA standard emergence test, the rate of emergence of seed treated with clothianidin was the same as the rate for the nontreated control, but imidaclopridand thiamethoxam-treated seed emerged more slowly than the nontreated control.

In previous evaluations of seed treatment insecticides, Pataky et al. (14) and Kuhar et al. (9) observed that insecticides did not control Stewart's wilt as effectively as resistance. Levels of control provided by $0.675 \mathrm{mg}$ a.i. imidacloprid or thiamethoxam generally were similar to the next level of resistance, e.g., incidence of Stewart's wilt was similar among insecticidetreated sweet corn hybrids that were susceptible to Stewart's wilt and nontreated hybrids that were moderately susceptible to Stewart's wilt (14). Although the need for seed treatment insecticides is greater for susceptible hybrids than for resistant hybrids, little information is available to forecast the incidence of Stewart's wilt on hybrids with different levels of resistance.

The Stevens-Boewe forecast $(2-4,15)$, which has been used for nearly 70 years as an imperfect predictor of the occurrence of Stewart's wilt, does not consider hybrid reaction. The ordinal categories of Stewart's wilt prevalence that are predicted from the Stevens-Boewe forecast (i.e., none, trace, slight, moderate, severe, destructive) may or may not be accurate depending on the level of resistance of the hybrid being grown. Pataky et al. (13) noted differences in incidence of Stewart's wilt among resistant, intermediate, and susceptible sweet corn hybrids in sequential plantings from April to late June in Delaware and Illinois. Michener et al. (10) described relationships between Stewart's wilt incidence and levels of resistance in sweet corn hybrids under various degrees of Stewart's wilt prevalence, but these relationships cannot be used to forecast Stewart's wilt incidence. Additional information from which to forecast the incidence or prevalence of Stewart's wilt on hybrids with different levels of resistance would be helpful in identifying situations in which seed treatment insecticides are necessary on hybrids with resistant, intermediate, or susceptible reactions to Stewart's wilt.

\section{ACKNOWLEDGMENTS}

We thank several companies that contributed to this project. Bayer CropScience AG, Gustafson LLC, and Syngenta Crop Protection provided partial financial support for this work and applied seed treatment insecticides. Seed of sweet corn hybrids was contributed by Rogers Seeds and Harris Moran Seeds. Field space and trial maintenance at Manito, IL, was provided by Del Monte Agricultural Research. We also thank John Francis of Bayer CropScience, Karen Arthur and Ray Knake of Gustafson, and Henry McLean and Dave Thomas of Syngenta Crop Protection for their comments and suggestions about these trials.

\section{LITERATURE CITED}

1. Andersch, W., and Schwarz, M. 2003. Clothianidin seed treatment (Poncho ${ }^{\circledR}$ ) - The new technology for control of corn rootworms and secondary pests in US-corn production. Pflanzenschutz-Nachr. Bayer 56:147-172.

2. Boewe, G. H. 1949. Late season incidence of Stewart's disease on sweet corn and winter temperatures in Illinois, 1944-1948. Plant Dis. Rep. 33:192-194.

3. Boewe, G. H. 1950. Stewart's wilt prospect for 1950. Plant Dis. Rep. 34:155.

4. Boewe, G. H. 1952. Stewart's wilt prospects in Illinois for 1952. Plant Dis. Rep. 36:238.

5. Braun, E. J. 1982. Ultrastructure investigation of resistant and susceptible maize infected with Erwinia stewartii. Phytopathology 72:159-166.

6. Carlson, G. A., and Main, C. E. 1976. Economics of disease-loss management. Annu. Rev. Phytopathol. 14:381-403.

7. Freeman, N. D., and Pataky, J. K. 2001. Levels of Stewart's wilt resistance necessary to prevent reductions in yield of sweet corn hybrids. Plant Dis. 85:1278-1284.

8. Jonitz, A., and Leist, N. 2003. Seed testing and the effect of insecticidal active ingredients on the germination and emergence of hybrid maize seed. Pflanzenschutz-Nachr. Bayer 56:173-207.

9. Kuhar, T. P., Stivers-Young, L. J., Hoffman, M. P., and Taylor, A. G. 2002. Control of corn flea beetle and Stewart's wilt in sweet corn with imidacloprid and thiamethoxam seed treatments. Crop Prot. 21:25-31.

10. Michener, P. M., Freeman, N. D., and Pataky, J. K. 2003. Relationships between reactions of sweet corn hybrids to Stewart's wilt and incidence of systemic infection by Erwinia stewartii. Plant Dis. 87:223-228.

11. Munkvold, G. P., McGee, D. C., and Iles, A. 1996. Effects of imidacloprid seed treatment of corn on foliar feeding and Erwinia stewartii transmission by the corn flea beetle. Plant Dis. 80:747-749.

12. Pataky, J. K., du Toit, L. J., Kunkel, T. E., and Schmitt, R. A. 1995. Severe Stewart's wilt in central Illinois on sweet corn hybrids moderately resistant to Erwinia stewartii. Plant Dis. 80:104.

13. Pataky, J. K., Hawk, J. A., Weldekidan, T., and Fallah Moghaddam, P. 1995. Incidence and severity of Stewart's bacterial wilt on sequential plantings of resistant and susceptible sweet corn hybrids. Plant Dis. 79:1202-1207.

14. Pataky, J. K., Michener, P. M., Freeman, N. D., Weinzierl, R. A., and Teyker, R. H. 2000. Control of Stewart's wilt in sweet corn with seed treatment insecticides. Plant Dis. 84:11041108 .

15. Stevens, N. E. 1934. Stewart's disease in relation to winter temperatures. Plant Dis. Rep. 18:141-149.

16. Suparyono and Pataky, J. K. 1989. Influence of host resistance and growth stage at the time of inoculation on Stewart's wilt and Goss's wilt development and sweet corn hybrid yield Plant Dis. 73:339-345. 